\title{
Astigmatism and vision: Should all astigmatism always be corrected?
}

\author{
James S Wolffsohn ${ }^{1}$, Gurpreet Bhogal ${ }^{1}$ and Sunil Shah ${ }^{1,2}$ \\ 1 Ophthalmic Research Group, Aston University, Birmingham, UK \\ 2 Midland Eye, Solihull, UK
}

As technology and medical devices improve, there is much interest in when and how astigmatism should be corrected with refractive surgery. Astigmatism can be corrected by most forms of refractive surgery, such as using excimer lasers algorithms to ablate the cornea to compensate for the magnitude of refractive error in different meridians. Correction of astigmatism at the time of cataract surgery is well developed and can be achieved through incision placement, relaxing incisions and toric intraocular lens (IOL) implantation. ${ }^{1}$ This was less of an issue in the past when there was less expectation to be spectacle independent after cataract surgery in which case the residual refractive error, including astigmatism, could be compensated for with spectacle lenses.

The issue of whether pre-surgical astigmatism should be corrected can be considered separately depending on whether a patient has residual accommodation and the type of refractive surgery under consideration. We have previously reported on the visual impact of full correction of astigmatism, rather than just correcting the mean spherical equivalent. Correction of astigmatism as low as $1.00 \mathrm{D}$ significantly improves both objective and subjective measures of functional vision in pre-presbyopes, both at distance and near. ${ }^{2}$

In presbyopes who have a monofocal distance correction, induced astigmatism (without spherical compensation) causes a greater loss in distance visual acuity with myopic than hyperopic astigmatism, regardless of the axis of the astigmatism; ${ }^{3}$ however it should be noted only monocular 
viewing was tested. At near, up to $1.00 \mathrm{D}$ of myopic astigmatism improves near visual acuity whereas hyperopic astigmatism makes near acuity worse. ${ }^{3}$ In this issue of the British Journal of Ophthalmology, the paper by Thomas Kohnen's group took a similar approach to investigate the effect of uncorrected astigmatism using lenses to induced astigmatism without compensating for the change in mean spherical equivalent. However the authors examined the effect of the uncorrected astigmatism on more functional vision, in the form of reading speed with the Salzberg Reading Desk. Their patients were pre-presbyopes, but the eyes were cyclopleged to simulate presbyopia. Reading speed and threshold reading acuity decreased with increasing uncorrected astigmatism, even as low as $-0.75 \mathrm{D}$. The effect was greater (worse) with with-the-rule compared to against-the-rule astigmatism for both reading speed and threshold reading acuity. This finding supports publications on patient's vision after monofocal IOL implantation (targeted for distance) following cataract surgery in whom distance and near vision is typically better in those who have against-the-rule astigmatism compared to those that have either with-the-rule or oblique astigmatism. ${ }^{5,6}$ Astigmatism also plays a role in increasing the depth of focus of patients with healthy corneas and following laser refractive surgery. ${ }^{7}$

In presbyopes where simultaneous vision multifocal refractive correction has been applied, the magnitude of residual astigmatism also impacts visual performance. In 2000, Hayashi and coworkers tested monocular visual acuity with a range of defocusing lenses (a defocus curve) for different levels of induced astigmatism. They showed that when induced post-operative astigmatism was up to $1.00 \mathrm{D}$, then multifocal intraocular lenses achieved 'good' visual acuity at both distance and near, although the induced astigmatism reduced distance vision compared to monofocal IOL corrected control patients. ${ }^{8} \mathrm{~A}$ similar finding has been found with several more current IOL multifocal designs with a bench adaptive optic system. ${ }^{9}$ This seems to be borne out by multifocal intraocular lens toric studies that show a significant improvement in distance and near visual acuity 
following implantation. ${ }^{10,11}$ In clinical studies, residual astigmatism is one of the most significant aetiologies of dissatisfaction after multifocal IOL implantation. ${ }^{12}$ Residual astigmatism also affects the visual result of other forms of refractive surgery for presbyopia. For example, modelling of the optics of corneal inlays suggests that higher levels of astigmatism should be corrected to optimise the depth of focus. ${ }^{13}$

Many studies on the impact of uncorrected astigmatism, such as the study published in this issue, induced the astigmatic effect so that different powers and orientations can be investigated in a repeated-measures design, so are the results applicable to adapted astigmats? Correcting the aberrations of keratoconic eyes does not lead to the gain in visual acuity predicted ${ }^{14}$ perhaps due to long established neural adaptation. ${ }^{15}$ However, it is not clear whether re-adaptation to vision through a less optically aberrated cornea is possible in the longer term. Adaption to astigmatism seems to occur, at least in relatively young subjects, in a matter of minutes, although the adaptation is orientation dependant. ${ }^{16,17}$ Astigmats who have not been fully corrected previously have been shown to be adapted to their astigmatism, but correction reduces this preference within a week. ${ }^{18}$ However, the effect of age on ability and rate of adaptation is not clear. It has also been indicated that there is an adaptation long-term memory and binocular interactive effects. ${ }^{19}$ Correcting astigmats of $1.00 \mathrm{D}$ or greater with a toric intraocular lens has been shown to result in better distance visual acuity than those corrected with a monofocal best sphere suggesting limited longterm adaptation effects that should concern a refractive surgeon, although near acuity was not measured and the effect was not stratified by the level of astigmatism corrected. ${ }^{20}$

In conclusion, the clinical evidence suggests that correction of astigmatism of 1.00D or greater will positively impact the outcome of refractive surgery. In presbyopic patients not being considered for 
a simultaneous vision multifocal correction, surgeons should be careful not to reduce low levels of against-the-rule astigmatism as this may aid the patient's post-surgical spectacle independence. The age related change from with, to against-the-rule, astigmatism is fortuitously beneficial to increasing the range of clear focus in the presbyope. ${ }^{21}$ Neural adaptation is unlikely to be a long term consideration in patients with astigmatism so surgeons should not shy away from its full correction in all other patients. 


\section{References}

1 Amesbury EC, Miller KM. Correction of astigmatism at the time of cataract surgery. Curr Opion Ophthalmol 2009;20:19-24.

2 Wolffsohn JS, Bhogal G, Shah S. Effect of uncorrected astigmatism on vision. J Cataract Refract Surg 2011;37:454-460.

3 Singh A, Pesala V, Garg P, Bharadwaj SR. Relation between uncorrected astigmatism and visual acuity in pseudophakia. Optom Vis Sci 2013;90:378-84

4 Casagrande M, Baumeister M, Bühren J, et al. Influence of additional astigmatism on distance corrected near visual acuity and reading performance. Br J Ophthalmol In Press

5 Nagpal KM, Desai C, Trivedi RH, et al. Is pseudophakic astigmatism a desirable goal? Indian J Ophthalmol 2000;48:213-6.

6 Nanavaty MA, Vasavada AR, Patel AS, et al. Analysis of patients with good uncorrected distance and near vision after monofocal intraocular lens implantation. J Cataract Refract Surg 2006;32:1091-7.

7 Yeu E, Wang L, Koch DD. The effect of corneal wavefront aberrations on corneal pseudoaccommodation. Am J Ophthalmol 2012;153:972-81.

8 Hayashi K, Hayashi H, Nakao F, Hayashi F. Influence of astigmatism on multifocal and monofocal intraocular lenses. Am J Ophthalmol 2000;130:477-82.

9 Zheleznyak L, Kim MJ, MacRae S, Yoon G. Impact of corneal aberrations on through-focus image quality of presbyopia-correcting intraocular lenses using an adaptive optics bench system. J Cataract Refract Surg 2012;38:1724-33.

10 Mojzis P, Pinero DP, Ctvrteckova V, Rydlova I. Analysis of internal astigmatism and higher order aberrations in eyes implanted with a new diffractive multifocal toric intraocular lens. Graefes Arch Clin Exp Ophthalmol 2013;251:341-8.

11 Mojzis P, Pinero DP, Studeny P, et al. Comparative analysis of clinical outcomes obtained with a new diffractive multifocal toric intraocular lens implanted through two types of corneal incision. J Cataract Refract Surg 2011;27:647-56.

12 de Vries NE, Webers $\mathrm{CAB}$, Touwslager WRH, et al. Dissatisfaction after implantation of multifocal intraocular lenses. J Cataract Refract Surg 2011;37:859-65.

14 Sabesan R, Yoon G (2009) Visual performance after correcting higher order aberrations in keratoconic eyes. J Vis 9(5): 1-10.

15 Sabesan R, Yoon G (2010) Neural Compensation for Long-term Asymmetric Optical Blur to Improve Visual Performance in Keratoconic Eyes. Invest Ophthalmol Vis Sci 51: 3835-3839.

16 Sawides L, Marcos S, Ravikumar S, et al. Adaptation to astigmatic blur. J Vis 2010;10:22. 
17 Ohlendorf A, Tabernero J, Schaeffel F. Neuronal adaptation to simulated and opticallyinduced astigmatic defocus. Vision Res 2011;51:529Y34.

13 Tabernero J, Artal P. Optical modeling of a corneal inlay in real eyes to increase depth of focus: Optimum centration and residual defocus. J Cataract Refract Surg 2012;38:270-7.

18 Vinas M, Sawides L, de Gracia P, Marcos S. Perceptual adaptation to the correction of natural astigmatism. PLoS One 2012;7:e46361.

19 Yehezkel O, Sagi D, Sterkin A, et al. Learning to adapt: Dynamics of readaptation to geometrical distortions. Vis Res 2010;50:1550-8.

20 Sasaki H, Yoshida M, Manabe S, et al. Effects of the toric intraocular lens on correction of pre-existing corneal astigmatism. Jpn J Ophtalmol 2012;56:445-52.

21 Hayashi K, Masumoto M, Fujino S, Hayashi F. Change in corneal astigmatism with aging. Nippon Ganka Gakkai Zasshi 1993;97:1193-6 